\title{
Intramammary antimicrobial treatment of subclinical mastitis and cow performance later in lactation
}

\author{
Bart H. P. van den Borne, ${ }^{1 *}$ Gerdien van Schaik, ${ }^{2,3}$ Theo J. G. M. Lam, ${ }^{2,3}$ Mirjam Nielen, ${ }^{3}$ and Klaas Frankena ${ }^{4}$ \\ ${ }^{1}$ Business Economics Group, Wageningen University, PO Box 8130, 6700 EW Wageningen, the Netherlands \\ ${ }^{2}$ GD Animal Health, PO Box 9, 7400 AA Deventer, the Netherlands \\ ${ }^{3}$ Department of Farm Animal Health, Faculty of Veterinary Medicine, Utrecht University, Yalelaan 7, $3584 \mathrm{CL}$ Utrecht, the Netherlands \\ ${ }^{4}$ Adaptation Physiology Group, Wageningen University, PO Box 338, $6700 \mathrm{AH}$, Wageningen, the Netherlands
}

\section{ABSTRACT}

The aim of this study was to evaluate long-term therapeutic effects of antimicrobial treatment of recently acquired subclinical mastitis (RASCM) during lactation. Quarter-level clinical mastitis (CM) followup, composite somatic cell counts (SCC), and cow-level milk yield later in lactation were evaluated using followup data from 2 previously published linked randomized field trials. The first trial randomly assigned antimicrobial treatment with any intramammary product or negative control to culture-positive quarters of cows having a first elevated composite SCC after 2 consecutive low composite SCC measurements. Untreated cows that had a second elevated composite SCC at the next measurement and were staphylococci-positive (i.e., Staphylococcus aureus or non-aureus staphylococci) were randomly assigned to treatment or control. Quarter-level CM cases were reported by the participating herd personnel, and milk yield and composite SCC data were obtained from the regular test-day recording. Frailty survival models were used to evaluate the longterm therapeutic effects of antimicrobial treatment of RASCM on quarter-level CM follow-up. Mixed linear regression models were applied to quantify the effect on milk yield and composite SCC. Data of 638 quarters from 486 cows in 38 herds were available for statistical analyses, of which 229 quarters of 175 cows received antimicrobial treatment for RASCM. Antimicrobial treatment culminated in reduced composite SCC levels later in lactation but did not result in different milk yield levels or CM follow-up compared with control cows. Antimicrobial treatment of cows with RASCM should therefore only be considered in exceptional situ-

Received January 4, 2019.

Accepted January 9, 2019.

*Corresponding author: bart.vandenborne@wur.nl ations given the current focus on antimicrobial usage reduction in animal husbandry.

Key words: antimicrobial, clinical mastitis, milk yield, somatic cell count, dairy cow

\section{INTRODUCTION}

Bovine subclinical mastitis (SCM) results in economic losses to the dairy farmer (Hogeveen et al., 2011). Cows with SCM produce less milk, have a higher composite SCC (CSCC) and a higher probability of developing clinical mastitis (CM), and are culled earlier than their healthy herd mates (Reksen et al., 2006, 2007; van den Borne et al., 2011). Additionally, cows with IMI may be a source of infection to other cows because some pathogens are contagious and thus can spread between cows (Lam et al., 1996; Zadoks et al., 2001; Barlow et al., 2013).

Antimicrobial treatment of SCM is one of the options to improve udder health in dairy herds. It is most commonly applied at drying-off but SCM may also be treated during lactation (Barkema et al., 2006; Barlow, 2011). Bacteriological cure of SCM after lactational antimicrobial treatment is affected by the causative pathogen (Deluyker et al., 2005; Barlow, 2011), treatment factors (Barkema et al., 2006), cow factors (Sol et al., 1997; Sandgren et al., 2008; Salat et al., 2008), pathogen strain characteristics (van den Borne et al., 2010b), and chronicity of infection (van den Borne et al., 2010c).

Antimicrobial treatment of SCM during lactation aims to reduce the duration of infection and prevent transmission of IMI to susceptible cows (Barkema et al., 2006; Barlow, 2011; Barlow et al., 2013). Bacteriological cure of subclinical IMI by antimicrobial treatment may also reduce SCC, culling, and CM through clinical flare-ups, and may improve milk yield of the treated cow during the remainder of lactation (Barkema et al., 2006; Barlow, 2011). These beneficial indirect effects are thought to be cost effective for the antimicrobial 
treatment of SCM caused by contagious mastitis pathogens during lactation (Keefe, 1997; Barlow et al., 2009; van den Borne et al., 2010a). In the short term (i.e., during the follow-up period until bacteriological cure had been evaluated), CM occurrence, culling, and milk yield did not differ between treated and untreated cows (Deluyker et al., 2005; Sandgren et al., 2008; van den Borne et al., 2010c). In one study on SCM caused by streptococci, fewer CM cases were observed in treated animals (St.Rose et al., 2003). Studies evaluating these potential beneficial indirect effects in the long term (i.e., after bacteriological cure evaluation), however, are scarce. The few studies published on long-term effects focused either on Staphylococcus aureus IMI (Barlow et al., 2013) or on chronic SCM (St.Rose et al., 2003; Sandgren et al., 2008). Beneficial indirect effects of antimicrobial treatment later in lactation might differ between recently acquired SCM (RASCM) and chronic SCM cases. The aim of this study was to investigate the effect of antimicrobial treatment of RASCM on CM follow-up, CSCC, and milk yield later in lactation.

\section{MATERIALS AND METHODS}

Data on short-term therapeutic effects of lactational antimicrobial treatment of bovine RASCM were obtained from 2 linked randomized field trials published previously (van den Borne et al., 2010c). Follow-up data on CM, CSCC, and milk yield were collected in addition to the 2 field trials as described below.

\section{Description of Study Design and Short-Term Data}

The 2 linked randomized field trials were conducted in 39 Dutch dairy herds, mainly consisting of HolsteinFriesian dairy cows, from December 2006 to May 2008. Herds were participating in monthly (every $4 \mathrm{wk}$ ) milk recording and had an average incidence of first elevated CSCC of more than $10 \%$ per test day. In trial 1, quarter milk samples were aseptically collected within $10 \mathrm{~d}$ after milk recording $(\mathrm{d}-7)$ from cows with an elevated CSCC ( $\geq 150,000$ cells $/ \mathrm{mL}$ for primiparae and $\geq 250,000$ cells/mL for multiparae) after 2 test days with CSCC measurements below the parity-specific thresholds. Bacteriological culturing, quarter SCC determination, and $\beta$-lactamase testing of Staph. aureus isolates were initiated within $24 \mathrm{~h}$ after sample collection. Quarters that were culture-positive for Staph. aureus, Streptococcus uberis, Streptococcus dysgalactiae, other nonagalactiae streptococci, or NAS, and having a quarter SCC $\geq 100,000$ cells $/ \mathrm{mL}$ were randomly allocated antimicrobial treatment or no treatment at the cow level. Pre-intervention milk samples from quarters with a quarter $\mathrm{SCC} \geq 100,000$ cells $/ \mathrm{mL}$ were taken again at d 0 , and antimicrobial treatment was initiated directly afterward. Untreated control cows that had a second elevated CSCC measurement in the next milk recording were eligible for enrollment in trial 2. Untreated control cows that did not have a second elevated CSCC measurement remained in trial 1 . In trial 2, quarter milk sampling and laboratory tests were repeated and cows with staphylococci-positive (i.e., Staph. aureus or NAS) quarters were randomly allocated to treatment or untreated control. Streptococci-positive cows were not enrolled in the second trial. Cows were randomized in a ratio of 1:1 for treatment and control but a ratio of 1:4 was used for staphylococci-positive cows in trial 1 to have sufficient staphylococci-positive cows to enroll in trial 2 (van den Borne et al., 2010c). In both trials, treatment was administered by farmers at $\mathrm{d} 0$ with any registered antimicrobial product commercially available for intramammary treatment. Milk samples from all treated and control quarters were taken at $\mathrm{d}$ 21 and 28 after treatment allocation in both trials. Bacteriological cure of a quarter was defined as absence of a pathogen that was originally was present at $d-7$ in both milk samples after treatment. Further details on study design and data collected within this 28-d followup period were described previously (van den Borne et al., 2010c). Laboratory results of milk samples were not communicated to the farmers during the trials except when a cow had to be treated for the study. Farmers received all laboratory results after the last samples had been collected, accompanied by written advice on how to improve mastitis management in their herds.

\section{Data Collection on Clinical Mastitis, CSCC, and Milk Yield}

In addition to the data collected in the previously described studies (van den Borne et al., 2010c), data were collected after the 28-d follow-up period to evaluate the performance of enrolled cows later in lactation. Farmers reported cow identification, date, and quarter location of all CM cases in their herds during the followup period. Clinical mastitis was defined as a quarter with visible abnormalities of the udder or milk or both. Farmers were instructed to aseptically collect a milk sample from each quarter with $\mathrm{CM}$ and to store it at $-20^{\circ} \mathrm{C}$ upon collection. Standard bacteriological culturing procedures (Harmon et al., 1990) were performed to identify the causative pathogen. Farmers reported dates of culling and drying off. Data collection in each herd continued until 6 mo after the last enrolled cow completed the follow-up period (d 28) and thus varied across herds (van den Borne et al., 2010c). Compos- 
ite SCC and milk yield data of all enrolled cows were obtained from the regular test-day recordings (CRV, Arnhem, the Netherlands).

\section{Statistical Analysis}

Due to the study design, cows could participate in both trials. Data from trial 1 control cows that were also included in trial 2 were therefore excluded from the current statistical analyses to avoid biased estimates in cow performance later in lactation.

Data on CM occurrence, culling, and drying off was obtained from all participating herds. However, 3 herds did not complete data reporting until the end of the study period because of a lack of compliance by the farmer for this part of the study. Another 3 herds installed an automatic milking system during data collection. Observations from those 6 herds were therefore censored when data reporting ended or when an automatic milking system was installed. Finally, cows that were $\geq 400$ DIM at intervention (d 0) were excluded from analyses.

All statistical analyses were performed in SAS software (version 9.3; SAS Institute Inc., Cary, NC) using PROC PHREG and PROC MIXED.

Clinical Mastitis. Quarter-level Cox proportional hazards models were used to evaluate the effect of antimicrobial treatment on the hazard of a first $\mathrm{CM}$ follow-up case in quarters with RASCM. Recurrent CM events or CM events in other quarters of the same cow were not evaluated. A quarter became at risk for CM in the current study on the day the last milk sample was collected (d 28). Its failure time was determined until the first CM follow-up case or censoring. Censoring occurred on the day of culling, drying-off, when cows were $180 \mathrm{~d}$ at risk in the same lactation, or when the study ended. All available covariates (Table 1) were tested in bivariable Cox proportional hazards models. Treatment was forced into all models as the predictor of primary interest. All covariates associated with CM follow-up $(P<0.25)$, based on the type 3 test, were subsequently selected for multivariable survival analyses. Correlations between selected variables were determined using the Spearman correlation coefficient. The biologically more meaningful variable was maintained to avoid collinearity if risk factor pairs showed an absolute correlation $>0.5$. Multivariable survival analyses consisted of a forward selection procedure, starting with the covariate with the lowest $P$-value in the bivariable analysis, until newly added covariates did not significantly $(P<$ $0.10)$ contribute to the model. The forward selection procedure and the $P$-value $<0.10$ were chosen because of low statistical power resulting from a small number of first CM follow-up cases. All multivariable models were inspected for confounding, which was defined to occur when estimates changed $>25 \%$ when a covariate was added to the model. All 2-way interactions between the covariates in the final model, including antimicrobial treatment, were tested. The effect of clustering of quarters within cows within herds was evaluated by adding shared herd and cow frailty effects one at a time to the final statistical model. The frailty effect with the largest variance was selected among competing models.

The proportional hazards assumption was evaluated by the Grambsch-Therneau test (Grambsch and Therneau, 1994) using the SCHOEN macro for SAS, by plotting the scaled Schoenfeld residuals against survival time, and by the creation of time-dependent covariates of the variables contributing to the final statistical model. Model fit was evaluated by plotting Cox-Snell residuals against the cumulative hazard. Proportional hazards assumption and model fit were evaluated using the final model but without the frailty effect included. Evaluations of the proportional hazards assumption and model fit gave no reasons for concern.

Milk Yield and CSCC. The observational period for the statistical analyses of milk yield and CSCC started on the last test-day recording before trial enrollment $(\mathrm{d}-7)$ and ended at culling, drying off, 180 $\mathrm{d}$ after treatment evaluation in the same lactation, or when data collection at the herd level was terminated. Mixed linear regression models were used to evaluate the effect of treatment on milk yield and the natural logarithm of CSCC (LnCSCC) during lactation. A random intercept at the herd level was added to all models to adjust for clustering of cows within herds. A repeated effect was additionally added to adjust for correlation of multiple milk yield and LnCSCC measurements within cows. Based on the Akaike information criterion, the first-order autoregressive and moving average $[\operatorname{arma}(1,1)]$ correlation structure gave the best fit among 6 competing correlation structures (i.e., independent, compound symmetry, first-order autoregressive, Toeplitz, first-order autoregressive moving average, and unstructured) for both outcome variables. All available covariates (Table 1) were tested one at the time using mixed linear regression models with treatment forced into the models. Test-day parameters (Table 1) were included as time-varying predictors that could change at each test day. Days in milk and a correction for peak production $\left(\mathrm{e}^{-0.05 \cdot \mathrm{DIM}}\right)$ were additionally added to the models for milk yield to depict the lactation curve (Wilmink, 1987). A backward selection procedure with variables having an unconditional association $(P<0.25)$ with milk yield or LnCSCC, based on the type 3 test, was applied to identify co- 
variates significantly $(P<0.05)$ contributing to the final mixed linear regression models. The interaction term treatment $\times$ test-day measurement following trial enrollment was evaluated in both statistical models for milk yield and LnCSCC to evaluate the treatment effect over time. The interaction term DIM $\times$ parity was also evaluated for the statistical model for milk yield to correct for potential lactation curve differences between primiparae and multiparae. Other interaction terms were deemed biologically irrelevant.

Homoscedasticity was graphically assessed by plotting standardized residuals against predicted values and by applying the Score test (Breusch and Pagan, 1979). Normality of residuals was additionally assessed by graphical evaluation and determination of skewness and kurtosis.

Table 1. Covariates included (X) in the statistical models for quarter-level clinical mastitis (CM) follow-up, cow-level milk yield, and composite SCC

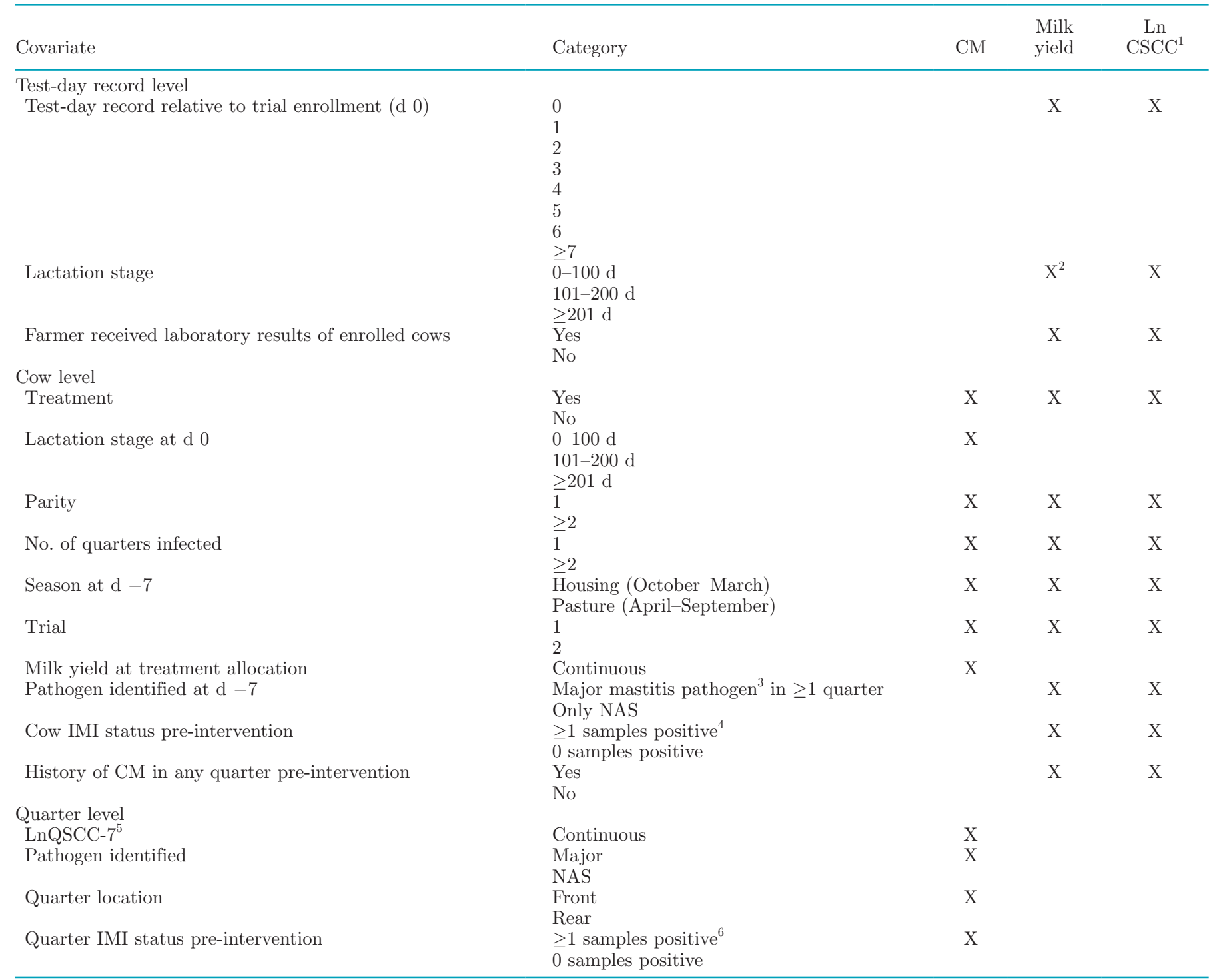

\footnotetext{
${ }^{1}$ Natural logarithm of test-day composite SCC.
}

${ }^{2}$ For this outcome variable, lactation stage was analyzed as a continuous variable and included a correction for peak production (Wilmink, 1987). ${ }^{3}$ Staphylococcus aureus, Streptococcus uberis, Streptococcus dysgalactiae, and other non-agalactiae streptococci.

${ }^{4}$ The same pathogen (as identified at $\mathrm{d}-7$ ) was also cultured from at least one other milk sample taken from the same cow pre-intervention.

${ }^{5}$ Natural logarithm of quarter SCC at d -7 .

${ }^{6}$ Compared with the pathogen identified at $\mathrm{d}-7$, the same pathogen was also cultured at other occasions in this quarter pre-intervention. 
Table 2. Factors associated with time to the first case of quarter-level clinical mastitis (CM; $\mathrm{n}=27)$ follow up within $180 \mathrm{~d}$ after randomization of lactational antimicrobial treatment to quarters with recently acquired subclinical mastitis $(\mathrm{n}=634)^{1}$

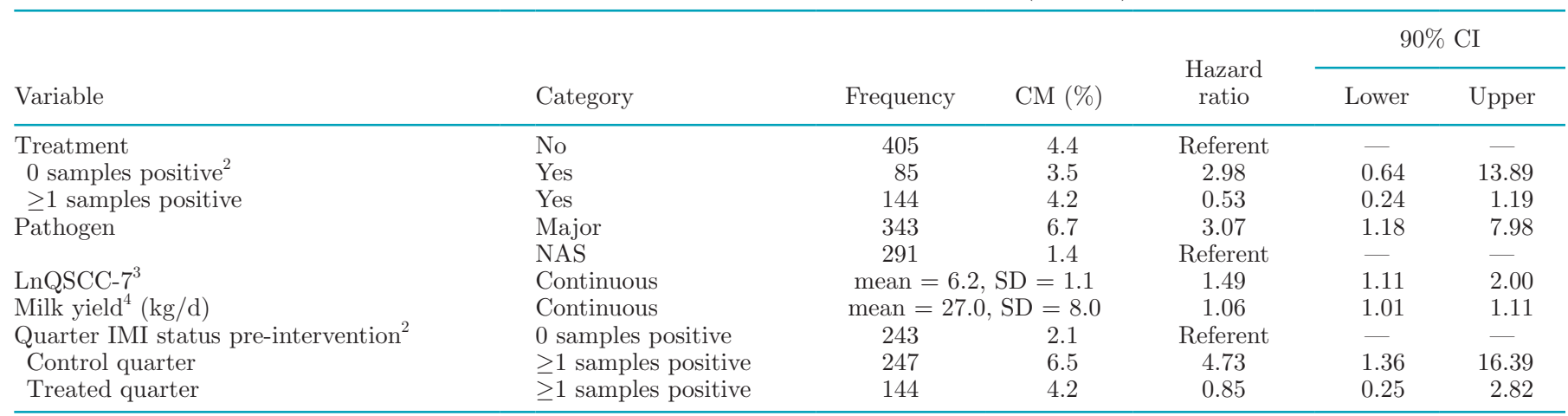

${ }^{1}$ Variance of the herd frailty effect was $0.49(\mathrm{SE}=0.44)$.

${ }^{2}$ Number of additional quarter milk samples culture-positive for the same pathogen pre-intervention compared with the pathogen identified at $\mathrm{d}-7$.

${ }^{3}$ Natural logarithm of quarter SCC at moment of intervention $(d-7)$.

${ }^{4}$ Milk yield at treatment allocation.

\section{RESULTS}

The data set contained 727 quarters with RASCM from 549 cows in 39 herds after removing trial 1 observations of cows that were enrolled in both trials. Of these, 89 quarter-level observations were excluded because cows were $>400$ DIM at SCM intervention (n $=31$ ), had CM during one of the trials $(\mathrm{n}=23)$, or were lost because the farmer stopped reporting information $(\mathrm{n}=35)$. Thereafter, the quarter-level data set consisted of 638 quarters with RASCM from 486 cows in 38 herds, of which 229 quarters of 175 cows received an antimicrobial treatment. Because of missing values, observations had to be excluded from the statistical analyses for CM follow-up $(\mathrm{n}=4)$, milk yield ( $\mathrm{n}=$ $18)$, and $\operatorname{LnCSCC}(\mathrm{n}=24)$, leaving 634 quarter-level observations and 3,028 and 3,022 test-day recordings available for the final statistical analyses of these indicators, respectively.

\section{Clinical Mastitis}

Median DIM at treatment allocation (d 0) was $90 \mathrm{~d}$ (range: 20-388) for quarters with CM follow-up and 168 d (range: 15-399) for quarters without CM follow-up. Twenty-seven quarters (4.2\%) showed a CM follow-up within $180 \mathrm{~d}$ after treatment evaluation. Median time to CM follow-up was $46 \mathrm{~d}$ (range: 3-165 d), whereas median time to censoring was $162 \mathrm{~d}$ (range: $0-180$ ) in quarters without $\mathrm{CM}$ follow-up. Only 7 milk samples for bacteriological culturing were taken by farmers from these $27 \mathrm{CM}$ follow-up cases. The same pathogen was determined as in the pre-intervention sample $(\mathrm{d}-7)$ in 3 of those samples. The other 4 milk samples were culture-negative $(\mathrm{n}=1)$ or the pathogen differed from the pathogen cultured at $\mathrm{d}-7(\mathrm{n}=3)$.

Antimicrobial treatment of RASCM was associated with time to quarter CM follow-up in an interaction term with "quarter IMI status pre-intervention" in the final frailty model, as presented in Table 2. This interaction term is further illustrated by Kaplan-Meier survival curves (Figure 1). Control quarters (without antimicrobial treatment) with multiple milk samples culture-positive for the same pathogen before randomization had a 4.7 times higher hazard for CM follow-up than quarters that were only culture-positive for the pathogen at $d-7$. Quarters with multiple milk samples culture-positive for the same pathogen before randomization that received treatment did not significantly differ in their CM follow-up rates from quarters that were culture-positive only once (hazard ratio $=0.85$ ) or that did not receive antimicrobial treatment (hazard ratio $=0.53)$. Quarters in which a major pathogen was identified at d 0 had a 3.1 times higher hazard for CM follow-up than quarters with a RASCM caused by NAS. Hazards for CM follow-up increased 1.5 and 1.1 times for each 1-unit increase in LnQSCC-7 (natural logarithm of quarter SCC at d -7) and daily milk yield, respectively.

\section{Milk Yield}

The results from the final mixed linear regression model for daily milk yield are presented in Table 3 and illustrated in Figure 2. Antimicrobial treatment of RASCM during lactation was not associated with milk yield following treatment allocation $(P=0.34$; Table $3)$. There was also no evidence for a therapeutic effect 


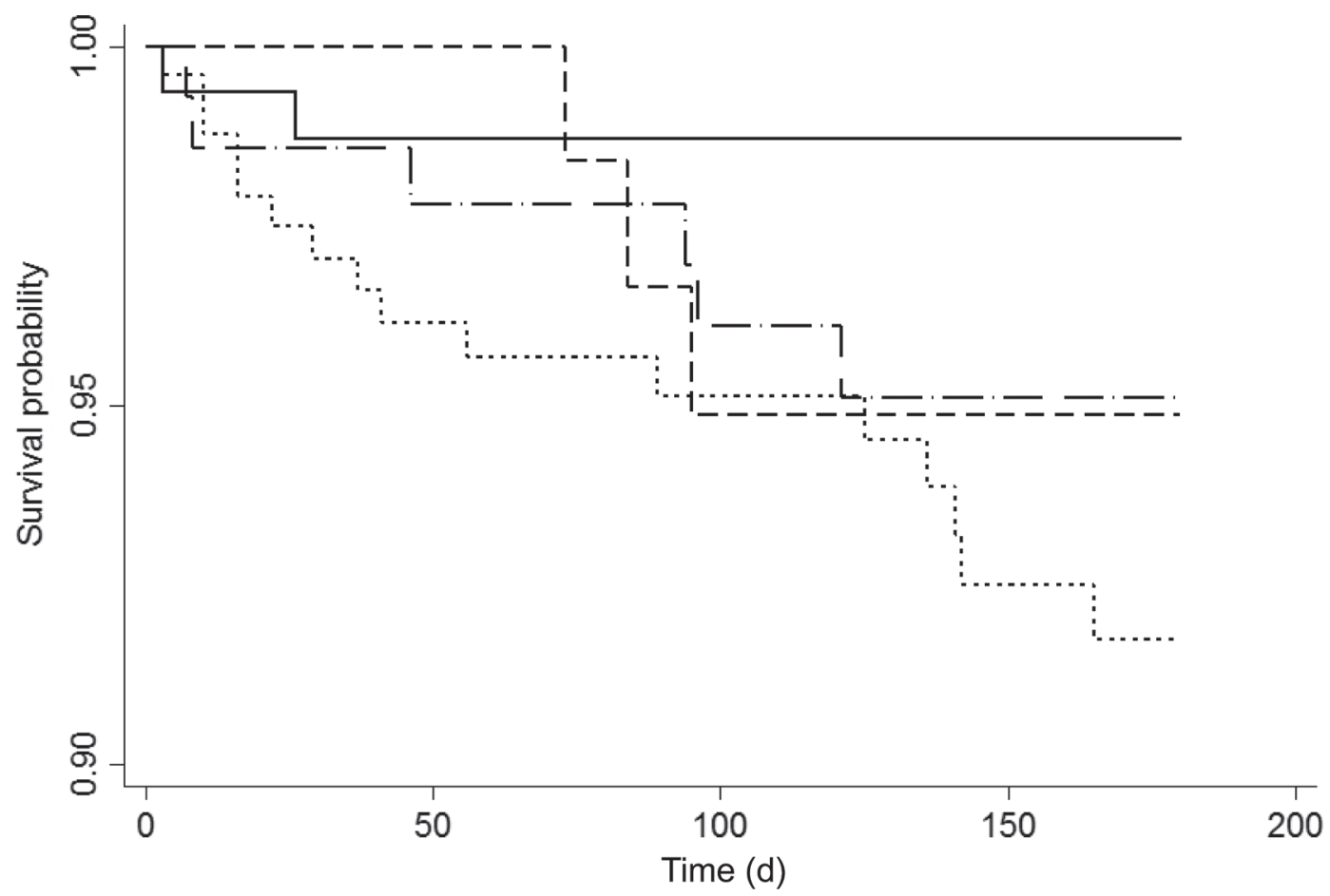

Figure 1. Kaplan-Meier survival plot of time to clinical mastitis follow-up in 4 groups of quarters: (solid line) control quarters with a single milk sample culture-positive pre-intervention, (dotted line) control quarters with multiple milk samples culture-positive pre-intervention, (dashed line) treated quarters with a single milk sample culture-positive pre-intervention, and (dashed-dotted line) treated quarters with multiple milk samples culture-positive pre-intervention.

over time as displayed by the nonsignificant interaction term between "treatment" and "test-day measurement following trial enrollment" ( $P=0.77$; Figure 2). The final statistical model was adjusted for the difference in lactation curves between primiparae and multiparae because the DIM $\times$ parity interaction term was significant.

The final linear mixed model for milk yield did not result in entirely normally distributed residuals. Removing 4 outliers, however, caused the residuals to become

Table 3. Factors associated with milk yield after randomization of antimicrobial treatment to 482 cows with recently acquired subclinical mastitis according to the final mixed linear regression model $^{1}$

\begin{tabular}{|c|c|c|c|c|c|}
\hline Variable & Category & $\begin{array}{c}\text { Frequency } \\
(\%)\end{array}$ & $\begin{array}{c}\text { Estimate } \\
(\mathrm{kg} / \mathrm{d})\end{array}$ & $\mathrm{SE}$ & $P$-value \\
\hline Intercept & & & 32.06 & 0.85 & $<0.01$ \\
\hline Treatment & Yes & 36.3 & -0.43 & 0.44 & 0.34 \\
\hline \multirow[t]{5}{*}{ Test-day record following trial enrollment } & 0 & 15.8 & Referent & & \\
\hline & 1 & 15.8 & -0.27 & 0.17 & 0.11 \\
\hline & 2 & 15.2 & -0.75 & 0.23 & $<0.01$ \\
\hline & 6 & 9.3 & -1.95 & 0.49 & $<0.01$ \\
\hline & $\geq 7$ & 7.6 & -1.83 & 0.55 & $<0.01$ \\
\hline \multirow[t]{2}{*}{ Parity } & $\geq 2$ & 66.6 & 8.62 & 0.77 & $<0.01$ \\
\hline & $\overline{1}$ & 33.4 & Referent & & \\
\hline DIM & Continuous & & -0.04 & 0.003 & $<0.01$ \\
\hline Peak production function & Continuous & & -15.07 & 0.92 & $<0.01$ \\
\hline
\end{tabular}

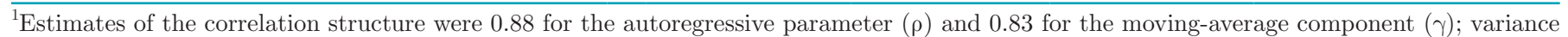
of the random herd effect was 10.84 ; residual variance was 28.85 . 


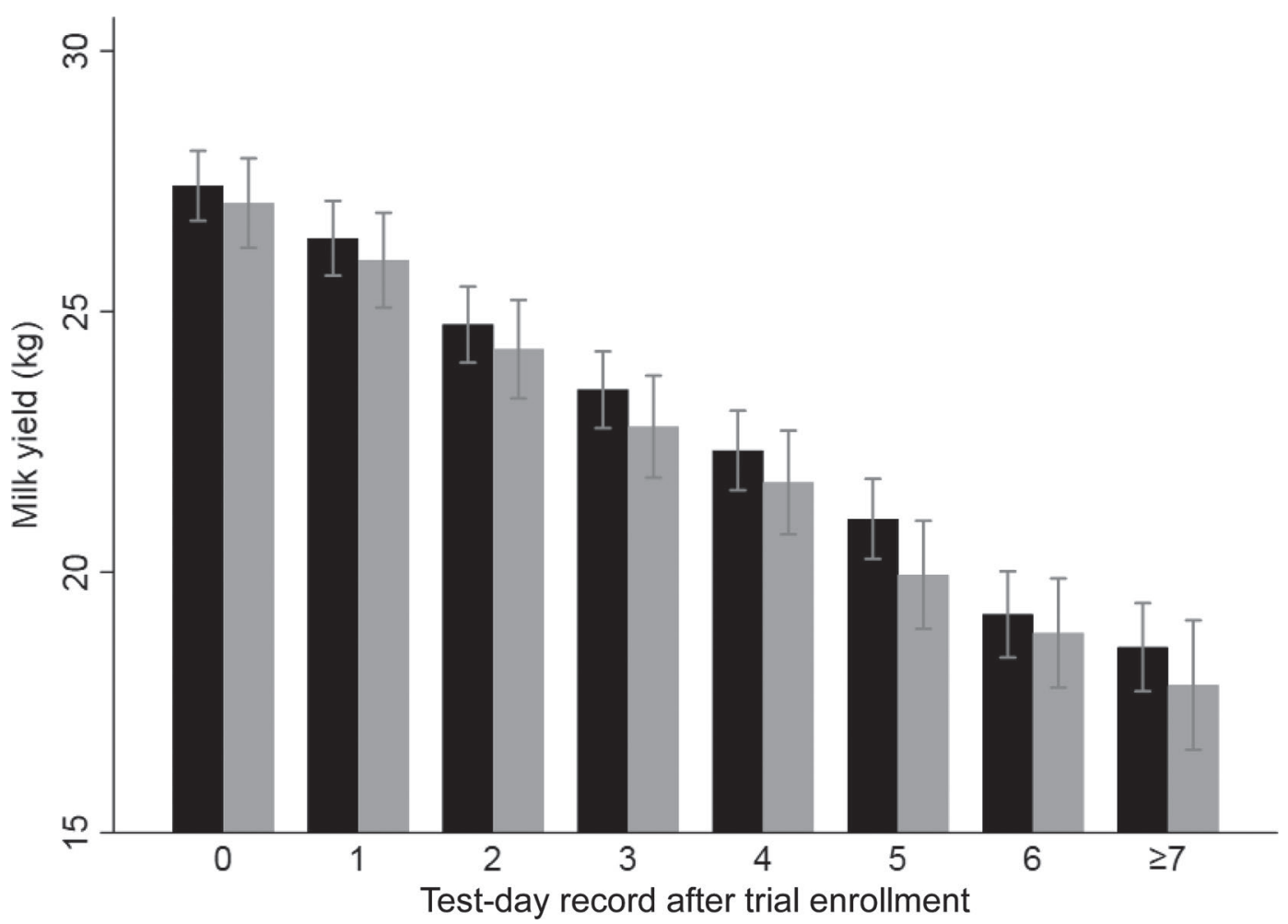

Figure 2. Predicted milk yield $(\mathrm{kg})$ and its $95 \%$ CI at test-day records after antimicrobial treatment of recently acquired subclinical mastitis in control cows (black) and treated cows (gray).

normally distributed and only marginally affected point estimates (results not shown). Graphical observation of standardized residuals and the significant Score test indicated that some heteroscedasticity was present. Standardized residuals showed a lower variance at predicted milk yield values below $15 \mathrm{~kg} / \mathrm{d}$, with a tendency toward positive values, indicating an underestimation of the model at lower milk yield levels.

\section{$\operatorname{LnCSCC}$}

The results of the final mixed linear regression model for LnCSCC are presented in Table 4 and illustrated in Figure 3; LnCSCC was lower after trial enrollment in both treated and control cows but LnCSCC reduction was more pronounced in cows receiving antimicrobial treatment. This was evident by the significant interaction term treatment $\times$ test-day following trial enrollment $(P<0.0001 ;$ Figure 3$)$. The difference in LnCSCC between treated and control cows remained significant until the fourth test-day record after enrollment. No difference was observed thereafter. Multiparae and cows with a major pathogen identified in one of the enrolled quarters had a significantly higher LnCSCC throughout the entire observational period. Cows originating from trial 2 (and thus had 2 consecutive high CSCC measurements at trial enrollment instead of 1) had a higher LnCSCC throughout the entire observational period compared with cows from trial 1.

\section{DISCUSSION}

In the first month after treatment allocation, antimicrobial treatment of SCM resulted in reduced quarter and composite SCC levels of the cows enrolled in the 2 linked randomized field trials (van den Borne et al., 2010c). As determined in the current study, these reduced CSCC levels persisted until the fourth test-day recording (i.e., 4 mo) after antimicrobial treatment. Similar effects have been observed previously (St.Rose et al., 2003; Salat et al., 2008; Sandgren et al., 2008). It should be noted, however, that only culture-positive quarters were treated in the trials used for the current study (van den Borne et al., 2010c), whereas all quarters of enrolled cows were treated with antimicrobials, via either the intramammary or the systemic route, in the previously conducted studies (St.Rose et al., 2003; Salat et al., 2008; Sandgren et al., 2008). Because IMI in untreated quarters may have gone unnoticed at trial enrollment, SCC reduction at the cow level may have 
Table 4. Factors associated with the natural logarithm of monthly composite SCC after randomization of antimicrobial treatment to 483 cows with recently acquired subclinical mastitis in the final mixed linear regression model ${ }^{1}$

\begin{tabular}{|c|c|c|c|c|c|}
\hline Variable & Category & $\begin{array}{c}\text { Frequency } \\
(\%)\end{array}$ & $\begin{array}{c}\text { Estimate } \\
(\mathrm{kg} / \mathrm{d})\end{array}$ & SE & $P$-value \\
\hline Intercept & & & 5.32 & 0.08 & $<0.01$ \\
\hline \multirow{6}{*}{ Test-day record following trial enrollment } & 0 & 15.8 & Referent & & \\
\hline & 1 & 15.8 & -0.46 & 0.05 & $<0.01$ \\
\hline & 2 & 15.1 & -0.41 & 0.06 & $<0.01$ \\
\hline & 5 & 10.7 & -0.40 & 0.07 & $<0.01$ \\
\hline & 6 & 9.4 & -0.40 & 0.08 & $<0.01$ \\
\hline & $\geq 7$ & 7.6 & -0.36 & 0.08 & $<0.01$ \\
\hline \multirow[t]{4}{*}{ Treatment $\times$ test-day record following trial enrolment } & $\overline{0}$ & & Referent & & \\
\hline & 1 & & -0.52 & 0.08 & $<0.01$ \\
\hline & 2 & & -0.41 & 0.09 & $<0.01$ \\
\hline & 3 & & -0.36 & 0.10 & $<0.01$ \\
\hline Parity & $\overline{1}$ & 33.5 & Referent & & \\
\hline \multirow[t]{2}{*}{ Trial } & 2 & 26.3 & 0.30 & 0.06 & $<0.01$ \\
\hline & 1 & 73.7 & Referent & & \\
\hline \multirow[t]{2}{*}{ Pathogen } & Major & 62.3 & 0.27 & 0.06 & $<0.01$ \\
\hline & NAS & 37.7 & Referent & & \\
\hline
\end{tabular}

${ }^{1}$ Estimates of the correlation structure were 0.75 for the autoregressive parameter $(\rho)$ and 0.54 for the moving-average component $(\gamma)$; variance of the random herd effect was 0.03 ; residual variance was 0.78 .

been underestimated. As expected, other covariates remained significant in the final model for CSCC. The covariate "trial" can be interpreted as an indicator for the duration of infection because CSCC measurement had to be high once or twice for trials 1 and 2, respectively. Finally, differences in CSCC between major and minor mastitis pathogens (Schukken et al., 2003) and parities (de Haas et al., 2002) have been observed previously.

The relationship between SCM and CM follow-up is well described in the literature (e.g., Green et al., 2004; Reksen et al., 2006; van den Borne et al., 2011). We hypothesized previously that $25 \%$ of all $\mathrm{CM}$ cases would be avoided if cows could be prevented from developing a high CSCC or if a perfect intervention could be applied to high CSCC cows (van den Borne et al., 2011). We therefore anticipated that antimicrobial treatment of RASCM would result in fewer CM followups, analogous to the studies of Barlow et al. (2013) and Sandgren et al. (2008). However, no such effect was observed in the current study. This was likely because of the late-lactation stage that most cows were in, resulting in a low overall incidence risk of CM follow-up (4\%; Olde Riekerink et al., 2008; van den Borne et al., 2010d). This, subsequently, resulted in low power to detect a statistically significant difference. Moreover, study designs differed, hampering a true comparison between the 3 investigations. In their study, Barlow and coworkers (2013) only treated Staph. aureus IMI, whereas other pathogens were also treated in the current study. Genotypes of Staph. aureus isolates differed too (van den Borne et al., 2010b; Barlow et al., 2013). Sandgren et al. (2008) observed a reduced cow-level CM incidence risk in cows that received an intramuscular antimicrobial treatment compared with untreated control cows and cows that received an intramammary antimicrobial treatment. In the current study, CM was followed up at the quarter level. An explorative survival analysis evaluating the effect of antimicrobial treatment on time to CM follow-up at the cow level did not identify a significant relationship either $(P=$ 0.34 ; results not shown). This probably results from the low statistical power at the cow level also (i.e., only 46 cases were observed, with incidence risks being 10.7 and $7.4 \%$ in control and treated cows, respectively). This cow-level performance indicator was therefore not scrutinized further.

Farmers were requested to take milk samples of all $\mathrm{CM}$ cases in their herd but only 7 of $27 \mathrm{CM}$ follow-up cases were sampled because of low compliance of farmers on this study protocol item. Conclusions about the relationship of the identified pathogens in samples from clinical and subclinical mastitis IMI could therefore 


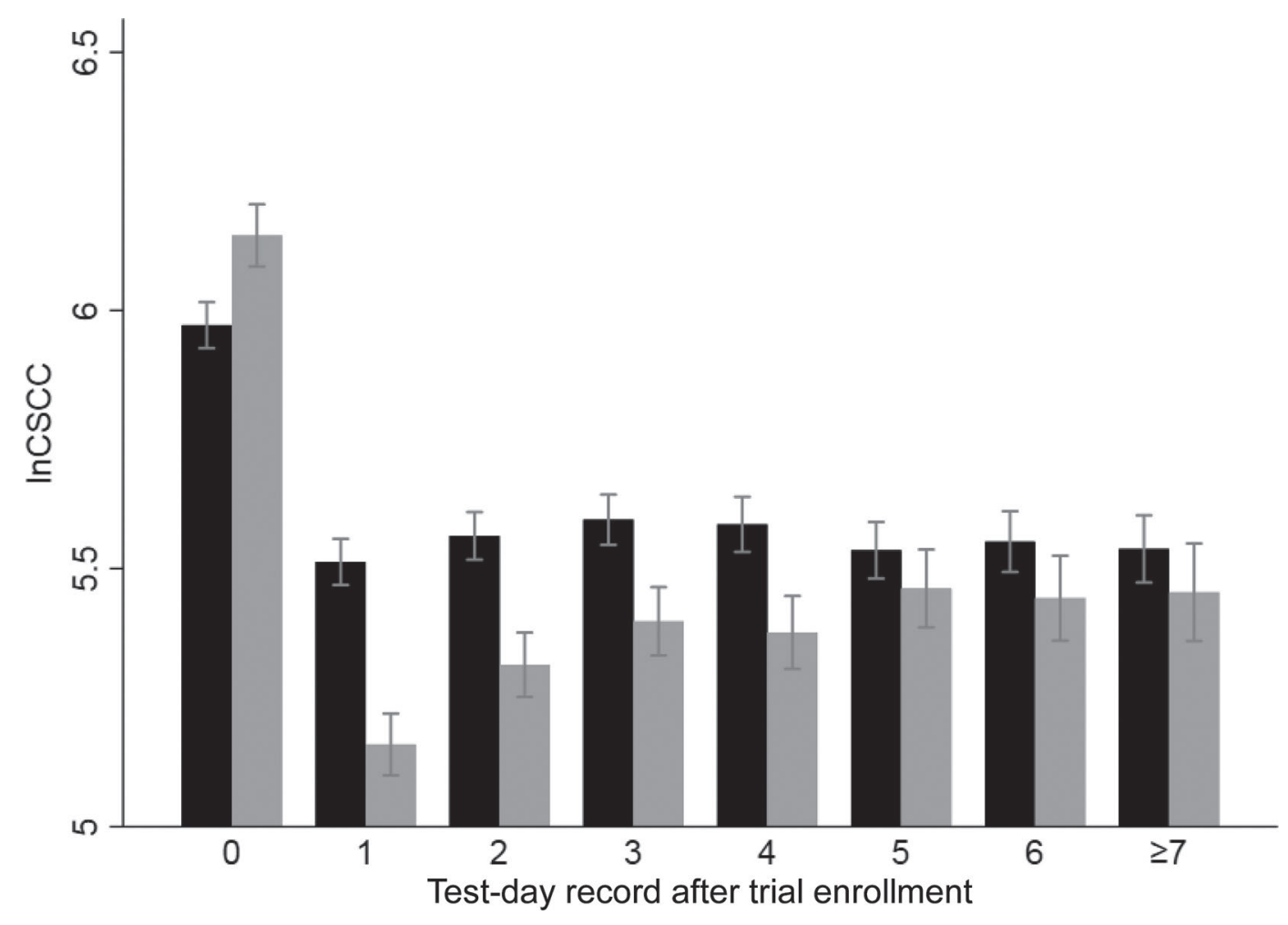

Figure 3. Predicted natural logarithm of composite SCC (lnCSCC) and its 95\% CI at test-day records after antimicrobial treatment of recently acquired subclinical mastitis in control cows (black) and treated cows (gray).

not be drawn. Control quarters with multiple culturepositive milk samples before treatment allocation had higher hazards for CM follow-up than control quarters with a single culture-positive milk sample. This observation might be a result of the bacteriological status of the quarter and the test characteristics of bacteriological culturing, low shedding of bacteria, false-positive milk samples because of contamination, or spontaneous cure, as discussed earlier (van den Borne et al., 2010c). The observed higher hazards for CM follow-up with increased LnQSCC-7 (natural logarithm of quarter SCC at $\mathrm{d}-7$ ) and milk yield levels and with IMI caused by major pathogens compared with lower yields and NAS IMI matched earlier studies (Green et al., 2004; Taponen and Pyörälä, 2009; van den Borne et al., 2011).

Milk yield in cows with chronic SCM was not affected by antimicrobial treatment in the studies of St.Rose et al. (2003) and Sandgren et al. (2008). The current study, focusing on RASCM, also provided no further evidence. Milk yield losses because of IMI therefore seem to be irreversible. Thus, when trying to preserve milk yield, focus should be on preventing new IMI in susceptible cows rather than on treating them.

Cow-level bioeconomic simulation models have been developed to investigate the cost-effectiveness of antimi- crobial treatment of subclinical IMI caused by streptococci and Staph. aureus during lactation (Swinkels et al., 2005a,b; Steeneveld et al., 2007). These models showed that cost-effectiveness depends on both cow and herd characteristics and that antimicrobial treatment only seems profitable at the cow level if transmission of IMI to susceptible cows is high. Given the lack of difference in milk yield and CM follow-up in the current study, antimicrobial treatment of RASCM is most likely not profitable. Lactational antimicrobial treatment of NAS IMI is not assumed to be cost effective either (Bexiga et al., 2011). On the herd level, however, antimicrobial treatment of RASCM might be cost effective for herds that receive a penalty for high bulk milk SCC because of the reduction in SCC. Moreover, antimicrobial treatment of SCM seems profitable for contagious pathogens because of the prevention of new IMI in susceptible cows (Keefe, 1997; Barlow et al., 2009; van den Borne et al., 2010a). The results from this study can be used to update the models developed previously.

Treating RASCM with antimicrobials during lactation results in increased antimicrobial usage, which does not coincide with the current focus on reducing antimicrobial usage in animal husbandry. Based on the results of our current and earlier work, we see no reason 
to propagate the routine use of antimicrobials to treat RASCM cases during lactation. Optimizing mastitis prevention should be the first approach in all situations. Only in exceptional cases should antimicrobial treatment of SCM caused by contagious pathogens during lactation be considered.

\section{CONCLUSIONS}

Using follow-up data from 2 previously conducted linked randomized field trials, long-term effects of antimicrobial treatment of RASCM were determined. Antimicrobial treatment of RASCM resulted in lower CSCC later in cows' lactation compared with untreated control cows. No evidence was found for a beneficial long-term effect of antimicrobial treatment of RASCM on CM follow-up or milk yield. Lactational antimicrobial treatment of cows with RASCM should therefore not be the first option of choice when trying to improve udder health in dairy herds.

\section{ACKNOWLEDGMENTS}

All involved farmers and field personnel are greatly acknowledged for their participation in this study. We thank CRV (Arnhem, the Netherlands) for kindly providing test-day recording data.

\section{REFERENCES}

Barkema, H. W., Y. H. Schukken, and R. N. Zadoks. 2006. Invited review: The role of cow, pathogen, and treatment regimen in the therapeutic success of bovine Staphylococcus aureus mastitis. J. Dairy Sci. 89:1877-1895. https://doi.org/10.3168/jds.S0022 -0302(06)72256-1.

Barlow, J. 2011. Mastitis therapy and antimicrobial susceptibility: A multispecies review with a focus on antibiotic treatment of mastitis in dairy cattle. J. Mammary Gland Biol. Neoplasia 16:383-407. https://doi.org/10.1007/s10911-011-9235-Z.

Barlow, J. W., L. J. White, R. N. Zadoks, and Y. H. Schukken. 2009. A mathematical model demonstrating indirect and overall effects of lactation therapy targeting subclinical mastitis in dairy herds. Prev. Vet. Med. 90:31-42. https://doi.org/10.1016/j.prevetmed 2009.03.016.

Barlow, J. W., R. N. Zadoks, and Y. H. Schukken. 2013. Effect of lactation therapy on Staphylococcus aureus transmission dynamics in two commercial dairy herds. BMC Vet. Res. 9:28. https://doi.org/ 10.1186/1746-6148-9-28.

Bexiga, R., K. A. Ellis, C. L. Vilela, and D. J. Mellor. 2011. Deterministic model to evaluate the impact of lactational treatment of subclinical mastitis due to coagulase-negative staphylococci. J. Dairy Res. 78:318-325. https://doi.org/10.1017/S0022029911000483.

Breusch, T. S., and A. R. Pagan. 1979. A simple test for heteroscedasticity and random coefficient variation. Econometrica 47:12871294. https://doi.org/10.2307/1911963.

de Haas, Y., H. W. Barkema, and R. F. Veerkamp. 2002. The effect of pathogen-specific clinical mastitis on the lactation curve for somatic cell count. J. Dairy Sci. 85:1314-1323. https://doi.org/10 $.3168 / j d s . S 0022-0302(02) 74196-9$.

Deluyker, H. A., S. N. Van Oye, and J. F. Boucher. 2005. Factors affecting cure and somatic cell count after pirlimycin treatment of subclinical mastitis in lactating cows. J. Dairy Sci. 88:604-614. https://doi.org/10.3168/jds.S0022-0302(05)72724-7.

Grambsch, P. M., and T. M. Therneau. 1994. Proportional hazards tests and diagnostics based on weighted residuals. Biometrika 81:515-526.

Green, M. J., P. R. Burton, L. E. Green, Y. H. Schukken, A. J. Bradley, E. J. Peeler, and G. F. Medley. 2004. The use of Markov chain Monte Carlo for analysis of correlated binary data: Patterns of somatic cells in milk and the risk of clinical mastitis in dairy cows. Prev. Vet. Med. 64:157-174. https://doi.org/10.1016/j.prevetmed .2004.05.006.

Harmon, R. J., R. J. Eberhart, D. E. Jasper, B. E. Langlois, and R. A. Wilson. 1990. Microbiological procedures for the diagnosis of udder infection. 3rd ed. National Mastitis Council Inc., Arlington, VA.

Hogeveen, H., K. Huijps, and T. J. G. M. Lam. 2011. Economic aspects of mastitis: new developments. N. Z. Vet. J. 59:16-23. https: //doi.org/10.1080/00480169.2011.547165.

Keefe, G. P. 1997. Streptococcus agalactiae mastitis: A review. Can. Vet. J. 38:429-437.

Lam, T. J. G. M., M. C. M. De Jong, Y. H. Schukken, and A. Brand. 1996. Mathematical modelling to estimate efficacy of postmilking teat disinfection in split-udder trials of dairy cows. J. Dairy Sci. 79:62-70.

Olde Riekerink, R. G. M., H. W. Barkema, D. F. Kelton, and D. T. Scholl. 2008. Incidence rate of clinical mastitis on Canadian dairy farms. J. Dairy Sci. 91:1366-1377.

Reksen, O., L. Sølverød, A. J. Branscum, and O. Østerås. 2006. Relationships between milk culture results and treatment for clinical mastitis or culling in Norwegian dairy cattle. J. Dairy Sci. 89:2928-2937. https://doi.org/10.3168/jds.S0022-0302(06)72565 $-6$.

Reksen, O., L. Sølverød, and O. Østerås. 2007. Relationships between milk culture results and milk yield in Norwegian dairy cattle. J. Dairy Sci. 90:4670-4678. https://doi.org/10.3168/jds.2006-900.

Salat, O., F. Sérieys, B. Poutrel, L. Durel, and L. Goby. 2008. Systemic treatment of subclinical mastitis in lactating cows with penethamate hydriodide. J. Dairy Sci. 91:632-640. https://doi.org/ 10.3168/jds.2007-0174.

Sandgren, C. H., K. Persson Waller, and U. Emanuelson. 2008 Therapeutic effects of systemic or intramammary antimicrobial treatment of bovine subclinical mastitis during lactation. Vet. J. 175:108-117. https://doi.org/10.1016/j.tvjl.2006.12.005.

Schukken, Y. H., D. J. Wilson, F. Welcome, L. Garrison-Tikofsky, and R. N. Gonzalez. 2003. Monitoring udder health and milk quality using somatic cell counts. Vet. Res. 34:579-596.

Sol, J., O. C. Sampimon, J. J. Snoep, and Y. H. Schukken. 1997. Factors associated with bacteriological cure during lactation after therapy for subclinical mastitis caused by Staphylococcus aureus. J. Dairy Sci. 80:2803-2808.

Steeneveld, W., J. Swinkels, and H. Hogeveen. 2007. Stochastic modelling to assess economic effects of treatment of chronic subclinical mastitis caused by Streptococcus uberis. J. Dairy Res. 74:459-467. https://doi.org/10.1017/S0022029907002828.

St.Rose, S. G., J. M. Swinkels, W. D. Kremer, C. L. Kruitwagen, and R. N. Zadoks. 2003. Effect of penethamate hydriodide treatment on bacteriological cure, somatic cell count and milk production of cows and quarters with chronic subclinical Streptococcus uberis or Streptococcus dysgalactiae infection. J. Dairy Res. 70:387-394. https://doi.org/10.1017/S0022029903006460.

Swinkels, J. M., H. Hogeveen, and R. N. Zadoks. 2005a. A partial budget model to estimate economic benefits of lactational treatment of subclinical Staphylococcus aureus mastitis. J. Dairy Sci. 88:4273-4287.

Swinkels, J. M., J. G. A. Rooijendijk, R. N. Zadoks, and H. Hogeveen. 2005b. Use of partial budgeting to determine the economic benefits of antibiotic treatment of chronic subclinical mastitis caused by Streptococcus uberis or Streptococcus dysgalactiae. J. Dairy Res. 72:75-85. https://doi.org/10.1017/S0022029904000603.

Taponen, S., and S. Pyörälä. 2009. Coagulase-negative staphylococci as cause of bovine mastitis-Not so different from Staphylococ- 
cus aureus? Vet. Microbiol. 134:29-36. https://doi.org/10.1016/j .vetmic.2008.09.011.

van den Borne, B. H. P., T. Halasa, G. van Schaik, H. Hogeveen, and M. Nielen. 2010a. Bioeconomic modeling of lactational antimicrobial treatment of new bovine subclinical intramammary infections caused by contagious pathogens. J. Dairy Sci. 93:4034-4044. https: //doi.org/10.3168/jds.2009-3030.

van den Borne, B. H. P., M. Nielen, G. van Schaik, M. B. Melchior, T. J. G. M. Lam, and R. N. Zadoks. 2010b. Host adaptation of bovine Staphylococcus aureus seems associated with bacteriological cure after lactational antimicrobial treatment. J. Dairy Sci. 93:2550-2558. https://doi.org/10.3168/jds.2009-2971.

van den Borne, B. H. P., G. van Schaik, T. J. G. M. Lam, and M. Nielen. 2010c. Therapeutic effects of antimicrobial treatment during lactation of recently acquired bovine subclinical mastitis: Two linked randomized field trials. J. Dairy Sci. 93:218-233. https:// doi.org/10.3168/jds.2009-2567. van den Borne, B. H. P., G. van Schaik, T. J. G. M. Lam, and M. Nielen. 2010d. Variation in herd level mastitis indicators between primi- and multiparae in Dutch dairy herds. Prev. Vet. Med. 96:49-55.

van den Borne, B. H. P., J. C. M. Vernooij, A. M. Lupindu, G. van Schaik, K. Frankena, T. J. G. M. Lam, and M. Nielen. 2011. Relationship between somatic cell count status and subsequent clinical mastitis in Dutch dairy cows. Prev. Vet. Med. 102:265-273. https: //doi.org/10.1016/j.prevetmed.2011.07.013.

Wilmink, J. B. M. 1987. Adjustment of test-day milk, fat and protein yield for age, season and stage of lactation. Livest. Prod. Sci. $16: 335-348$.

Zadoks, R. N., H. G. Allore, H. W. Barkema, O. C. Sampimon, Y. T. Gröhn, and Y. H. Schukken. 2001. Analysis of an outbreak of Streptococcus uberis mastitis. J. Dairy Sci. 84:590-599. https://doi .org/10.3168/jds.S0022-0302(01)74512-2. 